\title{
Indirect Down-regulation of Tumor-suppressive let-7 Family MicroRNAs by LMO1 in Neuroblastoma
}

\author{
NORIHISA SAEKI ${ }^{1}$, AKIRA SAITO ${ }^{2}$, YUKI SUGAYA ${ }^{2}$, MITSUHIRO AMEMIYA $^{2}$ and HIROKI SASAKI ${ }^{3}$ \\ ${ }^{1}$ Division of Anatomy and Physiology, Okinawa Prefectural College of Nursing, Okinawa, Japan; \\ ${ }^{2}$ Statistical Genetics Analysis Division, StaGen Co. Ltd., Tokyo, Japan; \\ ${ }^{3}$ Department of Translational Oncology, National Cancer Center Research Institute, Tokyo, Japan
}

\begin{abstract}
Background/Aim: Overall survival for the highrisk group of neuroblastoma $(N B)$ patients still remains at 40 $50 \%$, necessitating the establishment of a curable treatment. LIM domain only 1 (LMO1) gene encoding a transcriptional regulator is an NB-susceptibility gene with a tumorpromoting activity. Previously we conducted chromatin immunoprecipitation and DNA sequencing analyses on $N B$ cell lines and identified 3 protein-coding genes regulated by LMO1. In this study, we extended our analyses to capture microRNA genes directly or indirectly regulated by LMO1. Materials and Methods: Using microarrays, we conducted a comparative gene expression analysis on an $N B$ cell line $S K$ $\mathrm{N}$-SH; between the cells with and without LMO1 suppression. Results: Overall, 18 microRNAs were identified to be indirectly down-regulated by LMO1 including 7 microRNAs of the let-7 family, whose cell proliferation inhibitory activity was observed. Conclusion: Target genes of the LMOIregulated microRNAs and their relevant pathways may be a potential therapeutic target.
\end{abstract}

Neuroblastoma (NB), the most common extracranial solid tumor in childhood, is a cause for approximately $15 \%$ of all paediatric cancer deaths (1). With recent progress in NB treatment, patient prognosis has been significantly improved; Overall survival (OS) for low-risk and intermediate-risk groups is now $>98 \%$ and $90-95 \%$, respectively. On the contrary, OS for the high-risk (HR) group is still at 40-50\%, and $50-60 \%$ of these patients have a relapse, for which no

This article is freely accessible online.

Correspondence to: Norihisa Saeki, Division of Anatomy and Physiology, Okinawa Prefectural College of Nursing, Yogi 1-24-1, Naha, Okinawa 902-0076, Japan. Tel: +81 988338885, Fax: +81 988335133, e-mail: saeki@ okinawa-nurs.ac.jp

Key Words: Neuroblastoma, pediatric cancer, LMO1, microRNA, let-7. option of curable treatment remains $(2,3)$. To improve the OS and quality of life for the HR group, the identification of novel therapeutic target molecules is imperative (4-6).

Previously, the LIM domain only 1 (LMOI) gene encoding a transcriptional regulator was identified as an NB susceptibility gene by a genome-wide association study (7). In the study, it was also revealed that both the presence of an NB-related allele of single-nucleotide polymorphism (SNP) rs110419 in the $L M O 1$ gene and the increased copy number of the gene contribute to augmented LMOI expression, and that LMO1 promotes proliferation of NB cells. Importantly, it was shown that the relation of the variation at rs110419 in $L M O 1$ as well as the increased copy number to NB is stronger in the HR group than in the nonHR group. Recently, the SNP rs 110419 was found to be located in an enhancer region of the gene and have an influence on its function (8). Consequently, it is likely that the transcriptional regulator LMO1 is involved in the regulation of expression of a variety of genes important for NB progression in HR patients, and it is anticipated that identification of the LMO1's regulatory targets may lead us to identify novel tumor-promoting molecular pathways in $\mathrm{NB}$, as well as novel therapeutic target molecules, especially for treatment of the HR group.

Previously, we conducted chromatin immunoprecipitation and DNA sequencing analyses on two NB cell lines, SK-N$\mathrm{SH}$ and LA-N-5 and identified 3 protein-coding genes regulated by LMO1 in the $2 \mathrm{NB}$ cells: LIM and senescent cell antigen-like domains 1 (LIMSI), Ras suppressor protein 1 (RSU1) and relaxin 2 (RLN2) (9). LIMS1 and RSU1 encode proteins functioning with integrin-linked kinase (ILK) in integrin adhesomes, and an ILK inhibiting compound Cpd22 inhibited proliferation of the NB cells in vitro (9-12). The findings suggest the possibility that in addition to the LIMS1/ILK pathway, more tumor-promoting pathways exist downstream of the LMO1-regulatory cascade.

As the previous study aiming at LMO1-regulated genes was limited to protein-coding genes, analyses were extended to microRNA genes in this study. MicroRNAs are known to 
have an important role in regulating gene function by binding to the 3' untranslated region (UTR) of target messenger RNAs (mRNAs) and suppressing their translation $(13,14)$. Therefore, it is likely that the mRNAs targeted by LMO1-regulated microRNAs are significantly involved in NB oncogenesis.

\section{Materials and Methods}

Cell line. The NB cell line SK-N-SH was provided from the European Collection of Cell Cultures and maintained in D-MEM (Wako Pure Chemical Industries, Ltd., Osaka, Japan) supplemented with $10 \%$ fetal calf serum. LA-N-5 was provided by the RIKEN BRC through the National Bio-Resource Project of the MEXT, Japan, and maintained in RPMI1640 (Life Technologies Japan Ltd., Tokyo, Japan) supplemented with $10 \%$ FCS. SK-N-BE (2) was obtained from ECACC and maintained in a 1:1 mixture of EMEM (Wako) and Ham's F12 (Wako) supplemented with $0.5 \%$ nonessential amino acids (Life Technologies) and 15\% FCS.

shRNA. Each shRNA construct was prepared by annealing the (a) strand to the (b) as follows: for shLMO1 (target sequence: 5'GGCATTGGACAAGTACTGG-3'), (a) 5'-tcgagGGtATTGGAtAAGT AtTGGttcaagagaCCAGTACTTGTCCAATGCC-tttttacgcgta-3' and (b) 5'-agcttacgcgtaaaaaaGGCATTGGAGAAGTACTGGtctcttgaaCCAаTACTTaTCCAATaCCc-3', for shGFP (target sequence: 5'GCTACCTGTTCCATGGCCAA-3'), (a) 5' - tcgagGCTAtCTGTTCC gTGGCCgAttcaagagaTTGGCCATGGAACAGGTAGtttttacgcgtg-3' and (b) 5'-gatccacgcgtaaaaaaCTACCTGTTCCATGGCCAAtctcttgaa TcGGCCAcGGAACAGaTAGCc-3'. The shRNA was inserted into pLVSIN-CMV neo (Takara Bio, Shiga, Japan) whose CMV promoter was replaced by hU6 promoter. To obtain viral particles, the pLVSINhU6-shRNA constructs were introduced into Lenti-X ${ }^{\mathrm{TM}}$ 293T Cells (Takara Bio) with Lenti-X ${ }^{\mathrm{TM}}$ HTX Packaging System (Takara Bio), and after $72 \mathrm{~h}$ ' incubation, the medium was collected and its viral titer (infection units $/ \mathrm{ml}$ ) was determined by transduction to HT1080 cells. The NB cell lines were transducted with lentivirus (> 100,000 infection units) in the presence of polybrene $(10 \mu \mathrm{g} / \mathrm{ml}$ in culture medium, Sigma-Aldrich, St. Louis, MO, USA).

Microarray expression analyses. Total RNA was extracted from SK-N-SH transduced with pLVSIN-shLMO1 or pLVSIN-shGFP, using Absolutely RNA miRNA Kit (Agilent Technologies, Santa Clara, CA, USA). Microarray expression analyses were performed with miRNA Complete Labeling and Hyb Kit (Agilent) and SurePrint G3 Human miRNA Microarray, Release 19.0 (Agilent), following a standard protocol recommended by the manufacturer. The data were analyzed using Agilent Feature Extraction Software (Agilent).

Real-time RT-PCR. For microRNA hsa-miR-3648, RT-PCR was conducted by converting about $10 \mathrm{ng}$ of total RNA to the first strand cDNA with TaqMan MicroRNA Reverse Transcription Kit (Life Technologies), followed by performing TaqMan MicroRNA Assay (Life Technologies, Applied Biosystems Assay ID: 464401). For mRNA, RT-PCR was performed by converting approximately $5 \mu \mathrm{g}$ of total RNA to the first strand cDNA with High Capacity cDNA Reverse Transcription Kit (Life Technologies), followed by conducting TaqMan Gene Expression
Table I. MicroRNA genes present in the vicinity of the peaks detected by ChIP-Seq for LMO1-targets.

\begin{tabular}{|c|c|c|c|}
\hline \multirow[t]{2}{*}{ Chromosome } & \multicolumn{2}{|c|}{ Peak position $^{\dagger}$} & \multirow[t]{2}{*}{ MicroRNA gene* } \\
\hline & From & To & \\
\hline 1 & 84315912 & 84315949 & hsa-mir-548ap \\
\hline 3 & 120131193 & 120132019 & hsa-mir-198 \\
\hline 5 & 134260148 & 134260380 & hsa-mir-4461 \\
\hline 5 & 134262667 & 134262849 & hsa-mir-4461 \\
\hline 5 & 134263306 & 134263645 & hsa-mir-4461 \\
\hline 21 & 9826946 & 9827631 & $\begin{array}{c}\text { hsa-mir-3648, } \\
\text { hsa-mir-3687 }\end{array}$ \\
\hline
\end{tabular}

$†$ The position is based on UCSChg 19. *Present within $5 \mathrm{~kb}$ from the peak position.

Assay (Life Technologies, Applied Biosystems Assay ID: Hs00231133_m1 for LMO1 and Pre-Developed TaqMan Assay Reagent for glyceraldehyde-3-phosphate dehydrogenase $(G A P D H))$. The PCR was performed for 40 cycles that included 2 steps of temperature: $95^{\circ} \mathrm{C}$ for $15 \mathrm{sec}$ and $60^{\circ} \mathrm{C}$ for $60 \mathrm{sec}$, using ABI PRISM 7900HT Sequence Detection System (Life Technologies). The relative transcript level was calculated using the $\mathrm{Ct}$ value of $G A P D H$ transcript as reference.

Down-regulation of GAPDH and western blot analyses. Control siRNA and siRNA for GAPDH suppression were purchased from BIONEER Corp, Daejeon, Korea, and introduced into NB cells using Lipofectamine RNAiMAX (Life Technologies). Using CelLytic-M Mammalian Cell Lysis/Extraction Reagent (SigmaAldrich) and Protease Inhibitor Cocktail (Sigma-Aldrich), cell lysates were prepared and loaded onto a $15 \%$ SDS-polyacrylamide gel. Immune blotting was performed with an anti-GAPDH, an antiActin and a HRP-conjugated anti-goat antibody (Santa Cruz Biotechnology, Dallas, Texas, USA). The signals were detected by Pierce Western Blotting Substrate Plus (Thermo Fisher Scientific, Yokohama, Japan).

Cell growth assay. A mirVana miRNA inhibitor for miR-3648 and a negative control were obtained from Life Technologies. The microRNA mimics and Negative control \#2 were purchased from BIONEER Corp. The NB cells were prepared in five wells of 96well plates $(10,000$ cells/well). The microRNA inhibitor and mimics were added to the wells (6 pmol/well) using Lipofectamine RNAiMAX (Life Technologies). The cells were incubated for $72 \mathrm{~h}$ and the growth was evaluated by MTT (3-(4,5-dimethylthiazol-2yl)-2,5-diphenyl tetrazolium bromide) assay using Cell Counting Kit-8 (Dojindo, Kumamoto, Japan).

\section{Results}

MicroRNA hsa-miR-3648 is a direct target of LMO1 regulation. In our previous study, we performed chromatin immunoprecipitation-DNA sequencing (ChIP-Seq) to identify LMO1-regulated genes using 2 NB cell lines SK- 

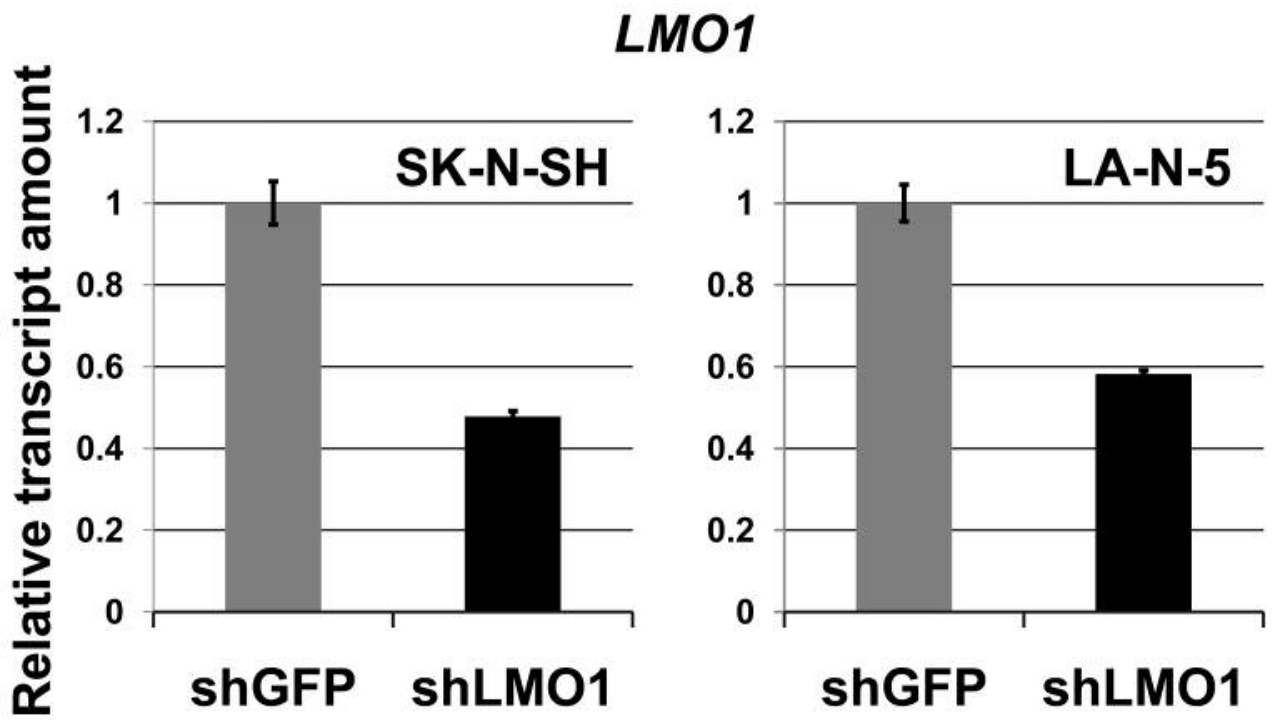

Figure 1. Down-regulation of LMO1 by shRNA (real-time RT-PCR). The shRNA for LMO1 (shLMO1) down-regulates LMO1 expression in NB cell lines, $S K-N-S H$ and LA-N-5, compared to the cells transfected with shRNA for green fluorescent protein (shGFP), statistical significance at $p<0.05$. Bar: Standard deviation.

N-SH and LA-N-5 (9). From the sequenced reads, those mapped to a reference genome sequence were selected for peak detection (in other word, for detection of candidates for LMO1-binding site) and applied to 6 peak-detection programs with 9 different settings. A definite peak was defined as the peaks detected by more than 5 of the 9 settings of the programs in each cell line (9). In this study, we focused on the definite peaks located in or near known microRNA genes (within a 5-kb proximity of known genes), common to the two cell lines, and identified 5 microRNA genes; hsa-mir-548ap, hsa-mir-198, hsa-mir4461, hsa-mir-3648 and hsa-mir-3687 (Table I). We examined the effect of $L M O 1$ suppression on these genes by performing microRNA microarray expression analyses, comparing the SK-N-SH NB cells in which LMOI was suppressed with shRNA, to its counterpart introduced with shRNA for a GFP gene as a reference (Figure 1). We listed the microRNAs that were down-regulated to half or less in NB cells following LMOI suppression, compared to reference (Table II). The hsa-mir-3648 (Table I) was one of the listed microRNAs and its down-regulation was confirmed by real-time RT-PCR in both SK-N-SH and LA$\mathrm{N}-5$ cells where $L M O 1$ expression was suppressed (Figure 2). Assuming that hsa-mir-3648 is an oncogenic microRNA up-regulated by LMO1, the consequence of inhibiting the microRNA in NB cells was examined. In addition to SK$\mathrm{N}-\mathrm{SH}$ and LA-N-5 cell lines, the SK-N-BE(2) cell line was used in the inhibition assay. The reason is that SK-N-SH and LA-N-5 have a low siRNA transfection efficiency and
SK-N-BE(2) is more permissive for siRNA transfection (Figure 3). An oligonucleotide inhibitor for hsa-mir-3648 was introduced into the three NB cell lines and showed a very weak but statistically significant suppressive effect on LA-N-5, however, it did not suppress cell proliferation of the other two cell lines. This suggests that hsa-mir-3648 may not be related to the cell-proliferation promoting activity of LMO1 or may have just a limited role in the LMO1 activity (Figure 4).

MicroRNAs of the let-7 family are indirectly regulated by LMO1. Next, we focused on microRNAs which were upregulated in SK-N-SH cells, in which LMO1 is suppressed. A total of 18 microRNAs were found to be up-regulated by 2- or more fold in SK-N-SH cells following suppression of LMO1 (Table III). As none of the 18 genes is a regulatory target of LMO1 identified by the ChIP-Seq analyses, all of them are likely to be under an indirect regulation by LMO1. Importantly, they included $h s a-m i R$ $34 a-5 p$ and let-7 family microRNAs which were previously reported to suppress the NB oncogene MYCN (15-17). We examined the effects of the 8 microRNA, $h s a$ miR-34a-5p, hsa-let-7a-5p, hsa-let-7b-5p, hsa-let-7c, hsalet-7e-5p, hsa-let-7f-5p, hsa-let-7g-5p and hsa-let-7i-5p, on cell proliferation by introducing their oligonucleotide mimic into NB cell lines. As a result, all the mimics showed a statistically significant inhibitory effect on the proliferation of, at least, one of the three cell lines (Figure $5)$. It is noteworthy that the inhibitory effect of the mimics 
Table II. MicroRNA down-regulated in SK-N-SH by LMO1 suppression.

\begin{tabular}{|c|c|c|c|c|c|}
\hline \multirow[t]{2}{*}{ MicroRNA } & \multicolumn{2}{|c|}{ shGFP } & \multicolumn{2}{|c|}{ shLMO1 } & \multirow{2}{*}{$\frac{\text { shLMO1/shGFF }}{\text { Log2 ratio }}$} \\
\hline & Signal* & Call $^{\dagger}$ & Signal* & $\mathrm{Call}^{\dagger}$ & \\
\hline hsa-miR-6165 & 19.3 & 1 & 0.1 & 0 & -7.59 \\
\hline hsa-miR-483-5p & 16.8 & 1 & 0.1 & 0 & -7.39 \\
\hline hsa-miR-4433-3p & 15.7 & 1 & 0.1 & 0 & -7.30 \\
\hline hsa-miR-4800-5p & 15.1 & 1 & 0.1 & 0 & -7.24 \\
\hline hsa-miR-4298 & 13.7 & 1 & 0.1 & 0 & -7.10 \\
\hline hsa-miR-4669 & 13.0 & 1 & 0.1 & 0 & -7.03 \\
\hline hsa-miR-125a-3p & 12.0 & 1 & 0.1 & 0 & -6.91 \\
\hline hsa-miR-4442 & 10.0 & 1 & 0.1 & 0 & -6.65 \\
\hline hsa-miR-4465 & 10.0 & 1 & 0.1 & 0 & -6.64 \\
\hline hsa-miR-4515 & 8.9 & 1 & 0.1 & 0 & -6.48 \\
\hline hsa-miR-4778-5p & 8.6 & 1 & 0.1 & 0 & -6.43 \\
\hline hsa-miR-937-5p & 8.5 & 1 & 0.1 & 0 & -6.42 \\
\hline hsa-miR-3648 & 8.4 & 1 & 0.1 & 0 & -6.38 \\
\hline hsa-miR-5195-3p & 8.2 & 1 & 0.1 & 0 & -6.35 \\
\hline hsa-miR-4417 & 8.1 & 1 & 0.1 & 0 & -6.33 \\
\hline hsa-miR-424-3p & 7.9 & 1 & 0.1 & 0 & -6.30 \\
\hline hsa-miR-4793-5p & 7.1 & 1 & 0.1 & 0 & -6.16 \\
\hline hsa-miR-6722-3p & 6.3 & 1 & 0.1 & 0 & -5.98 \\
\hline hsa-miR-1185-1-3p & 5.9 & 1 & 0.1 & 0 & -5.87 \\
\hline hsa-miR-4430 & 5.3 & 1 & 0.1 & 0 & -5.73 \\
\hline hsa-miR-3663-3p & 4.7 & 1 & 0.1 & 0 & -5.55 \\
\hline hsa-miR-1233-1-5p & 4.6 & 1 & 0.1 & 0 & -5.53 \\
\hline hsa-miR-6723-5p & 4.1 & 1 & 0.1 & 0 & -5.36 \\
\hline hsa-miR-874 & 3.8 & 1 & 0.1 & 0 & -5.26 \\
\hline hsa-miR-664b-5p & 3.8 & 1 & 0.1 & 0 & -5.26 \\
\hline hsa-miR-1249 & 3.6 & 1 & 0.1 & 0 & -5.15 \\
\hline hsa-miR-513a-5p & 3.4 & 1 & 0.1 & 0 & -5.11 \\
\hline hsa-miR-642b-3p & 24.8 & 1 & 4.2 & 1 & -2.56 \\
\hline hsa-miR-6510-5p & 40.1 & 1 & 7.4 & 1 & -2.43 \\
\hline hsa-miR-1268a & 680.3 & 1 & 151.7 & 1 & -2.17 \\
\hline hsa-miR-134 & 16.2 & 1 & 3.7 & 1 & -2.13 \\
\hline hsa-miR-4270 & 34.0 & 1 & 8.1 & 1 & -2.06 \\
\hline hsa-miR-1290 & 322.5 & 1 & 78.4 & 1 & -2.04 \\
\hline hsa-miR-4499 & 15.7 & 1 & 3.8 & 1 & -2.04 \\
\hline hsa-miR-575 & 37.2 & 1 & 10.8 & 1 & -1.78 \\
\hline hsa-miR-6126 & 13.4 & 1 & 3.9 & 1 & -1.77 \\
\hline hsa-miR-939-5p & 29.1 & 1 & 8.8 & 1 & -1.72 \\
\hline hsa-miR-4741 & 73.6 & 1 & 22.9 & 1 & -1.68 \\
\hline hsa-miR-663a & 22.3 & 1 & 7.1 & 1 & -1.65 \\
\hline hsa-miR-4745-5p & 18.0 & 1 & 5.8 & 1 & -1.65 \\
\hline hsa-miR-1234-5p & 492.4 & 1 & 165.6 & 1 & -1.57 \\
\hline
\end{tabular}

\begin{tabular}{|c|c|c|c|c|c|}
\hline \multirow[t]{2}{*}{ MicroRNA } & \multicolumn{2}{|c|}{ shGFP } & \multicolumn{2}{|c|}{ shLMO1 } & \multirow{2}{*}{$\frac{\operatorname{shLMO} 1 / \mathrm{shGFP}}{\log 2 \text { ratio }}$} \\
\hline & Signal* & Call $^{\dagger}$ & Signal* & $\mathrm{Call}^{\dagger}$ & \\
\hline hsa-miR-5703 & 224.3 & 1 & 76.1 & 1 & -1.56 \\
\hline hsa-miR-630 & 341.3 & 1 & 119.5 & 1 & -1.51 \\
\hline hsa-miR-5001-5p & 70.1 & 1 & 25.9 & 1 & -1.44 \\
\hline hsa-miR-4281 & 567.4 & 1 & 212.2 & 1 & -1.42 \\
\hline hsa-miR-4763-3p & 45.4 & 1 & 17.0 & 1 & -1.42 \\
\hline hsa-miR-1246 & 458.4 & 1 & 175.4 & 1 & -1.39 \\
\hline hsa-miR-4466 & 91.7 & 1 & 35.1 & 1 & -1.39 \\
\hline hsa-miR-6124 & 38.0 & 1 & 14.7 & 1 & -1.37 \\
\hline hsa-miR-371b-5p & 58.4 & 1 & 22.9 & 1 & -1.35 \\
\hline hsa-miR-574-5p & 15.2 & 1 & 6.0 & 1 & -1.34 \\
\hline hsa-miR-5100 & 13.8 & 1 & 5.6 & 1 & -1.31 \\
\hline hsa-miR-6088 & 218.6 & 1 & 88.3 & 1 & -1.31 \\
\hline hsa-miR-5787 & 724.7 & 1 & 296.6 & 1 & -1.29 \\
\hline hsa-miR-371a-5p & 13.0 & 1 & 5.4 & 1 & -1.26 \\
\hline hsa-miR-4532 & 30.3 & 1 & 12.7 & 1 & -1.25 \\
\hline hsa-miR-6090 & 649.2 & 1 & 284.7 & 1 & -1.19 \\
\hline hsa-miR-3196 & 105.7 & 1 & 46.4 & 1 & -1.19 \\
\hline hsa-miR-3656 & 60.0 & 1 & 26.6 & 1 & -1.17 \\
\hline hsa-miR-4787-5p & 79.4 & 1 & 35.3 & 1 & -1.17 \\
\hline hsa-miR-6087 & 1214.1 & 1 & 542.0 & 1 & -1.16 \\
\hline hsa-miR-6125 & 590.3 & 1 & 263.8 & 1 & -1.16 \\
\hline hsa-miR-1915-3p & 220.3 & 1 & 98.7 & 1 & -1.16 \\
\hline hsa-miR-2392 & 8.2 & 1 & 3.7 & 1 & -1.14 \\
\hline hsa-miR-1227-5p & 19.9 & 1 & 9.1 & 1 & -1.13 \\
\hline hsa-miR-3135b & 19.1 & 1 & 8.8 & 1 & -1.12 \\
\hline hsa-miR-940 & 11.8 & 1 & 5.4 & 1 & -1.12 \\
\hline hsa-miR-1973 & 74.1 & 1 & 34.6 & 1 & -1.10 \\
\hline hsa-miR-4530 & 386.5 & 1 & 182.0 & 1 & -1.09 \\
\hline hsa-miR-4534 & 49.8 & 1 & 23.7 & 1 & -1.07 \\
\hline hsa-miR-4516 & 4300.4 & 1 & 2066.1 & 1 & -1.06 \\
\hline hsa-miR-3940-5p & 18.7 & 1 & 9.0 & 1 & -1.05 \\
\hline hsa-miR-1202 & 116.2 & 1 & 56.2 & 1 & -1.05 \\
\hline hsa-miR-3665 & 120.2 & 1 & 58.7 & 1 & -1.03 \\
\hline hsa-miR-1229-5p & 60.9 & 1 & 29.8 & 1 & -1.03 \\
\hline hsa-miR-3679-5p & 57.7 & 1 & 28.9395 & 1 & -1.00 \\
\hline
\end{tabular}

*Exp gTotalGeneSignal (This signal is the sum of the total probe signals in the green channel per gene). ${ }^{\dagger} 1$ for detection of expression of mature microRNA, 0 for no detection.

\section{Discussion}

was clearly demonstrated especially in SK-N-BE(2), which display a much higher transfection efficiency for siRNA than SK-N-SH or LA-N-5.

Finally, the effect of the other 10 of the 18 microRNAs on cell proliferation was examined. Mimics for three microRNAs, hsa-miR-16-5p, hsa-miR-20b-5p and $h s a-m i R-$ 409-3p significantly suppressed cell growth of SK-N-BE(2) but not that of SK-N-SH or LA-N-5, which may reflect their differences in transfection efficiency (Figure 6).

In this study, hsa-miR-3648 was identified as a direct target of LMO1, however, no cell proliferation inhibitory activity of the microRNA was demonstrated in NB cells. There is no previous report on the functions of hsa-miR-3648. A recent report stated that hsa-miR-3648 is transcriptionally regulated in neural stem cells by the amyloid precursor protein (APP)derived cleavage product, APP intracellular domain (AICD) (18). Taken together with our results indicating that hsa-miR3648 is directly regulated by LMO1, we can suggest that 


\section{hsa-miR-3648}
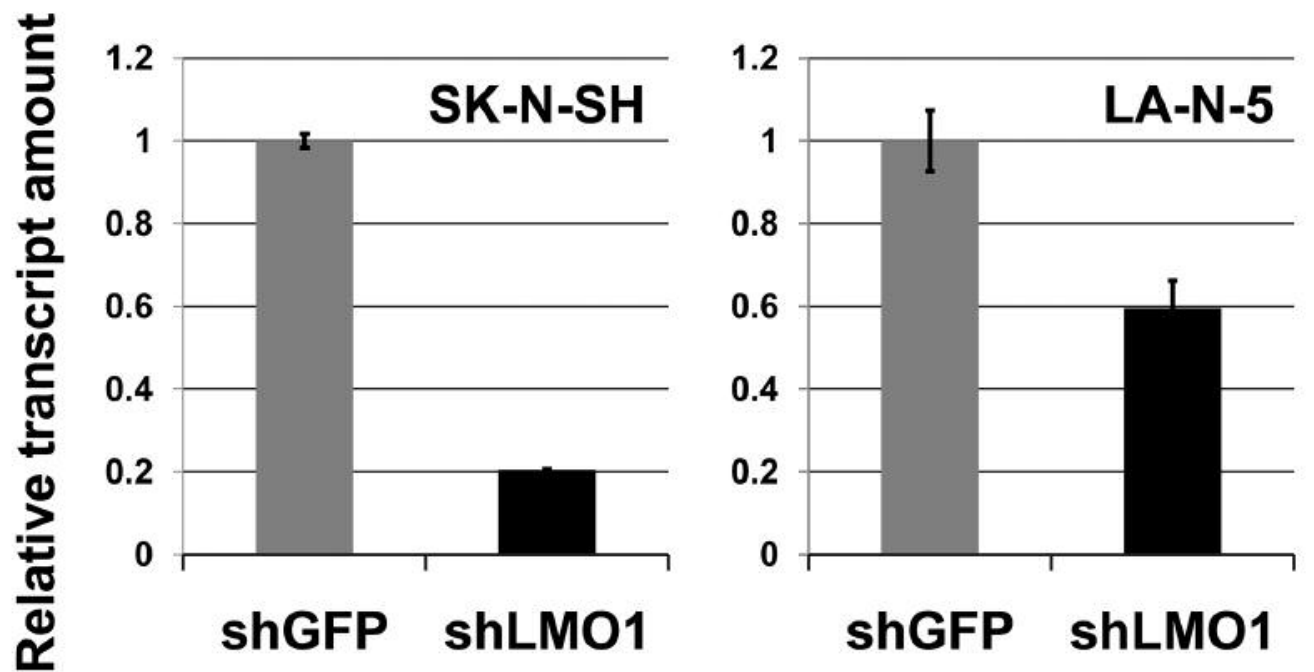

Figure 2. Down-regulation of hsa-mir-3648 by shRNA (real-time RT-PCR). The shRNA for LMO1 (shLMO1) down-regulates hsa-mir-3648 expression in NB cell lines, $S K-N-S H$ and LA-N-5, compared to the cells transfected with shRNA for green fluorescent protein (shGFP), statistical significance at $p<0.05$. Bar: Standard deviation.

AICD may cooperatively regulate the expression of hsa-miR3648 with LMO1 in NB cells.

The MYCN gene is the best-known oncogene that functions in $\mathrm{NB}$ and promotes cell proliferation, cell invasion and angiogenesis by regulating a variety of molecules (17). In the let-7 family, let-7e was demonstrated to bind to the 3' untranslated region of the $M Y C N$ transcript and inhibit its function, conferring a tumor suppressor activity in NB (15). Humans have 10 mature let-7 family members; let-7a, let-7b, let-7c, let-7d, let-7e, let-7f, let-7g, let-7i, mir-98 and mir-202 (19). Also, a tumor suppressive function of some let-7 family members was demonstrated in non-NB cancers. Stable transfection of let- $7 f$ reduced growth of thyroid cancer cells through inhibition of mitogen-activated protein kinase (20). It was reported that proliferation of lung cancer cells is suppressed by let-7a, let-7b, let-7c, let-7d and let-7g (21). Proliferation of nasopharyngeal carcinoma cell lines, HK1 and HONE1, was inhibited by let-7a, let-7b, let-7d, let-7e, let-7g and let-7i (22). By targeting MYH9 (Myosin, Heavy Chain 9, Non-Muscle) transcripts, let-7f inhibits invasion and metastasis of gastric cancer cells (23). A malignant phenotype of osteosarcoma cell lines, U2-OS and HOS, is changed by let-7 $g$ through inhibition of Aurora kinase B gene (24).

LIN28B is an RNA binding protein that binds to the terminal loop of let-7 microRNAs and inhibits processing of the microRNA (25). As silencing of LIN28B in NB cells upregulates expression of let-7a, let-7e, let-7g, let-7i, and mir98 , it is likely that these microRNAs are regulated by

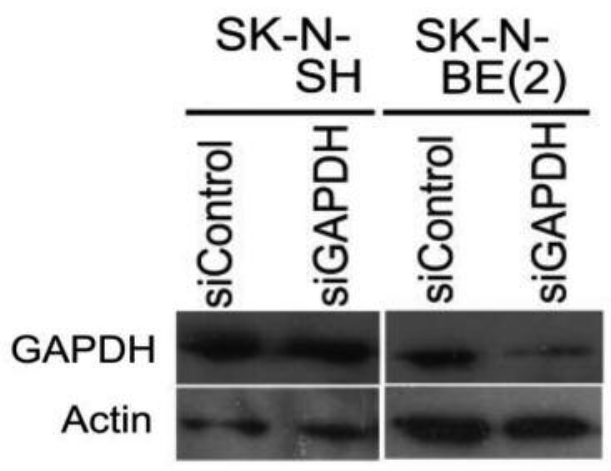

Figure 3. $S K-N-B E(2)$ is more permissive to siRNA transfection than $S K-N-S H$. A western blot analysis demonstrated that introduction of siRNA for GAPDH reduced the amount of the GAPDH in SK-N-BE(2) cells more that in $S K-N$-SH.

LIN28B (26). A genome wide association study revealed $L I N 28 B$ as an NB susceptibility gene, and Lin28b-transgenic mice develop NB (26). Intriguingly, Lin28 is down-regulated by let-7 and both molecules form a reciprocal autoregulatory loop that controls microRNA processing during embryonic neural stem cell commitment in mice (27).

In addition to the let-7 family, miR-34a was reported to target $M Y C N$ transcripts (16). It was also reported as a tumor suppressor that inhibits proliferation of NB cells through 

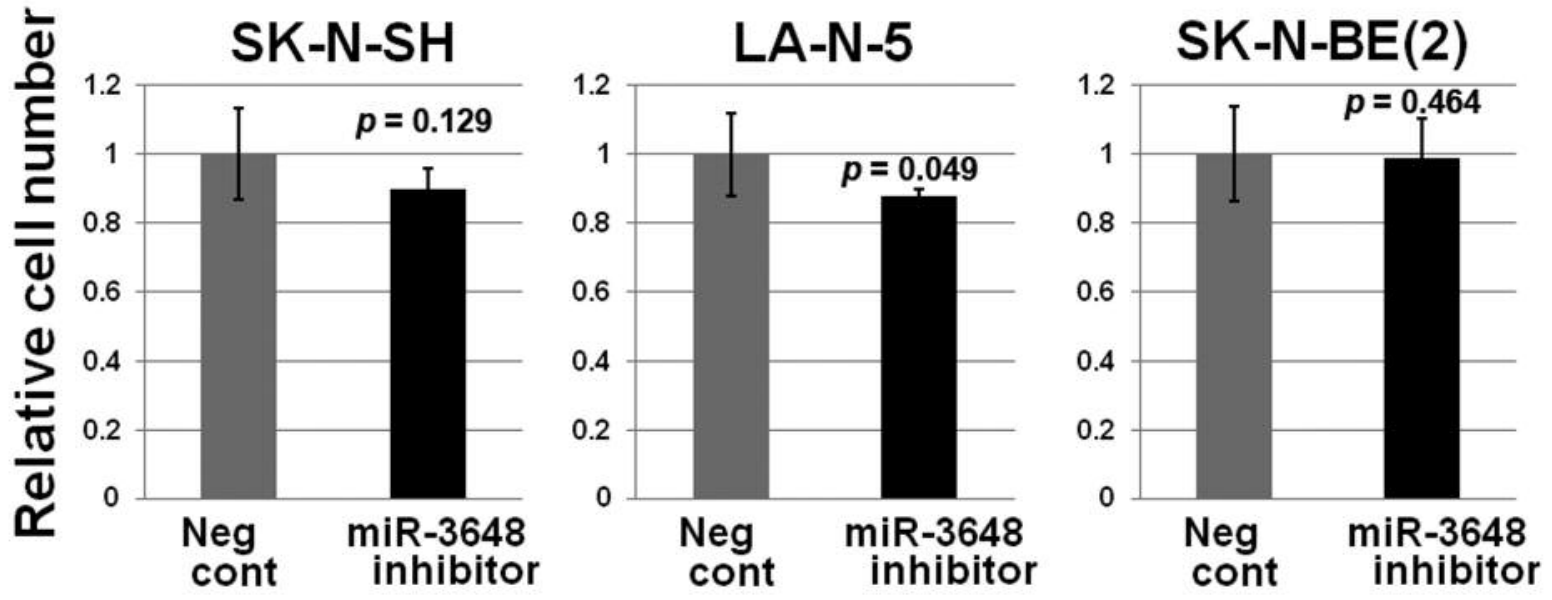

Figure 4. The microRNA hsa-mir-3648 has no cell-proliferation promoting activity (cell growth assay). Transfection of hsa-mir-3648 inhibitor into $N B$ cell lines showed no suppression of cell proliferation compared to negative control mimic (Neg cont). p-Value between the negative control (Neg Cont) and the inhibitor is shown. Bar: Standard deviation.

targeting mitogen-activated protein kinase kinase kinase 9 (MAP3K9) transcripts $(28,29)$.

Besides the 7 microRNAs of the let-7 family and miR$34 \mathrm{a}$, this study detected 10 microRNAs indirectly suppressed by LMO1. Among these, miR-20b, miR-16 and miR-409 were clearly demonstrated to have a cell proliferation activity on SK-N-BE(2) (Table III, Figure 6). However, their targets in normal adrenal tissue or NB remain to be elucidated. Upregulation of miR-20b expression was reported in gastric, breast and colorectal cancers and it is thought to act as an oncomir (30-32). However, an inhibitory activity of miR-20b on proliferation, migration and invasion of bladder cancer cells was also demonstrated (33). It may have a role in both tumor progression and suppression in a cancer typedependent manner. It was reported that cisplatin downregulates the expression of brain-derived neurotropic factor, a member of the neurotropin family associated with aggressive malignant behavior by targeting miR-16 and resulting in inhibition of cell proliferation of the NB cell line SH-SY5Y (34). miR-409 suppresses cancer cell invasion and metastasis by targeting a pro-metastatic gene radixin in gastric cancers (35).

The results of this study suggest that LMO1 executes its oncogenic function in NB, partly by down-regulating several tumor suppressive microRNAs.

\section{Acknowledgements}

This work was supported by the National Cancer Center Research and Development Fund (No. 23-B-18) and by JSPS KAKENHI Grant Number 26670510.
Table III. MicroRNA up-regulated in SK-N-SH by LMO1 suppression.

\begin{tabular}{|c|c|c|c|c|c|}
\hline \multirow[t]{2}{*}{ MicroRNA } & \multicolumn{2}{|c|}{ shGFP } & \multicolumn{2}{|c|}{ shLMO1 } & \multirow{2}{*}{$\frac{\operatorname{shLMO} 1 / \text { shGFP }}{\log 2 \text { ratio }}$} \\
\hline & Signal* & Call ${ }^{\dagger}$ & Signal* & Call ${ }^{\dagger}$ & \\
\hline hsa-miR-34a-5p & 0.1 & 0 & 7.04682 & 821 & 6.14 \\
\hline hsa-miR-23a-3p & 0.1 & 0 & 5.7763 & 341 & 5.85 \\
\hline hsa-miR-99b-5p & 0.1 & 0 & 5.23699 & 991 & 5.71 \\
\hline hsa-miR-20b-5p & 0.1 & 0 & 5.05015 & 151 & 5.66 \\
\hline hsa-let-7i-5p & 0.1 & 0 & $4.8824 \mathrm{C}$ & 491 & 5.61 \\
\hline hsa-miR-106b-5p & 0.1 & 0 & 4.6930 & 041 & 5.55 \\
\hline hsa-miR-543 & 0.1 & 0 & 3.92212 & 121 & 5.29 \\
\hline hsa-let-7g-5p & 3.98429 & 1 & 16.964 & 1 & 2.09 \\
\hline hsa-let-7c & 16.1552 & 1 & 42.2622 & 1 & 1.39 \\
\hline hsa-let-7f-5p & 27.0994 & 1 & 70.6598 & 1 & 1.38 \\
\hline hsa-let-7b-5p & 15.5918 & 1 & 40.6471 & 1 & 1.38 \\
\hline hsa-miR-16-5p & 7.9961 & 1 & 20.0237 & 1 & 1.32 \\
\hline hsa-miR-125b-5p & 39.1198 & 1 & 92.9244 & 1 & 1.25 \\
\hline hsa-miR-342-3p & 10.0142 & 1 & 23.3954 & 1 & 1.22 \\
\hline hsa-miR-125a-5p & 7.70954 & 1 & 17.639 & 1 & 1.19 \\
\hline hsa-let-7a-5p & 92.7249 & 12 & 210.23 & 1 & 1.18 \\
\hline hsa-let-7e-5p & 27.6341 & 1 & 59.0392 & 1 & 1.10 \\
\hline hsa-miR-409-3p & 5.24178 & 1 & 11.1176 & 1 & 1.08 \\
\hline
\end{tabular}

*Exp gTotalGeneSignal (This signal is the sum of the total probe signals in the green channel per gene). ${ }^{\dagger} 1$ for detection of expression of mature microRNA, 0 for no detection.

\section{References}

1 Maris JM, Hogarty MD, Bagatell $\mathrm{R}$ and Cohn SL: Neuroblastoma. Lancet 369: 2106-2120, 2007.

2 Maris JM: Recent advances in neuroblastoma. N Engl J Med 362: 2202-2211, 2010. 


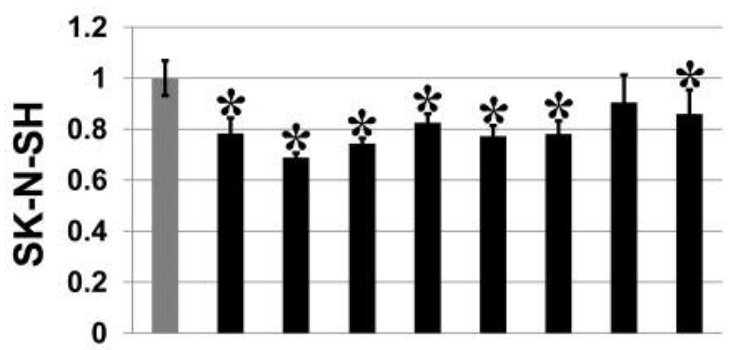

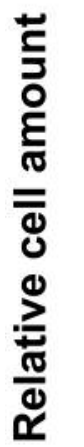
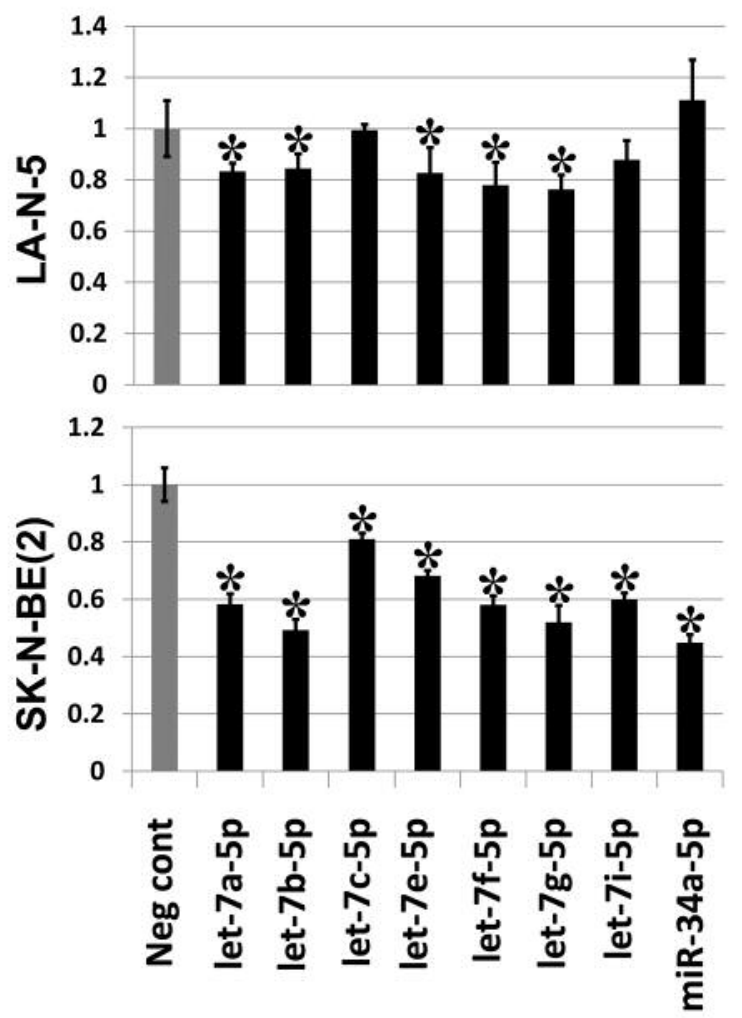

Figure 5. Seven let-7 family microRNA mimics and hsa-miR-34a-5p mimic suppress $N B$ cell growth. Introduction of mimic of each microRNA into NB cell lines resulted in reduction of cell proliferation compared to negative control mimic (Neg cont). Asterisks indicate statistical significance ( $p$-value less than 0.05) between the negative control (Neg cont) and the mimic. Bar: Standard deviation.

3 Morgenstern DA, Baruchel S and Irwin MS: Current and future strategies for relapsed neuroblastoma: challenges on the road to precision therapy. J Pediatr Hematol Oncol 35: 337-347, 2013.

4 Song HY, Rellinger EJ, Park SH, Paul P, Qiao J, Vasilopoulos A, Ozden O, Gius D and Chung DH: Inhibition of Sirtuin 6 induces neuroblastoma differentiation. Anticancer Res 38: 647-654, 2018.

5 Berger M and VON Schweinitz D: Therapeutic innovations for targeting childhood neuroblastoma: Implications of the neurokinin-1 receptor system. Anticancer Res 37: 5911-5918, 2017.

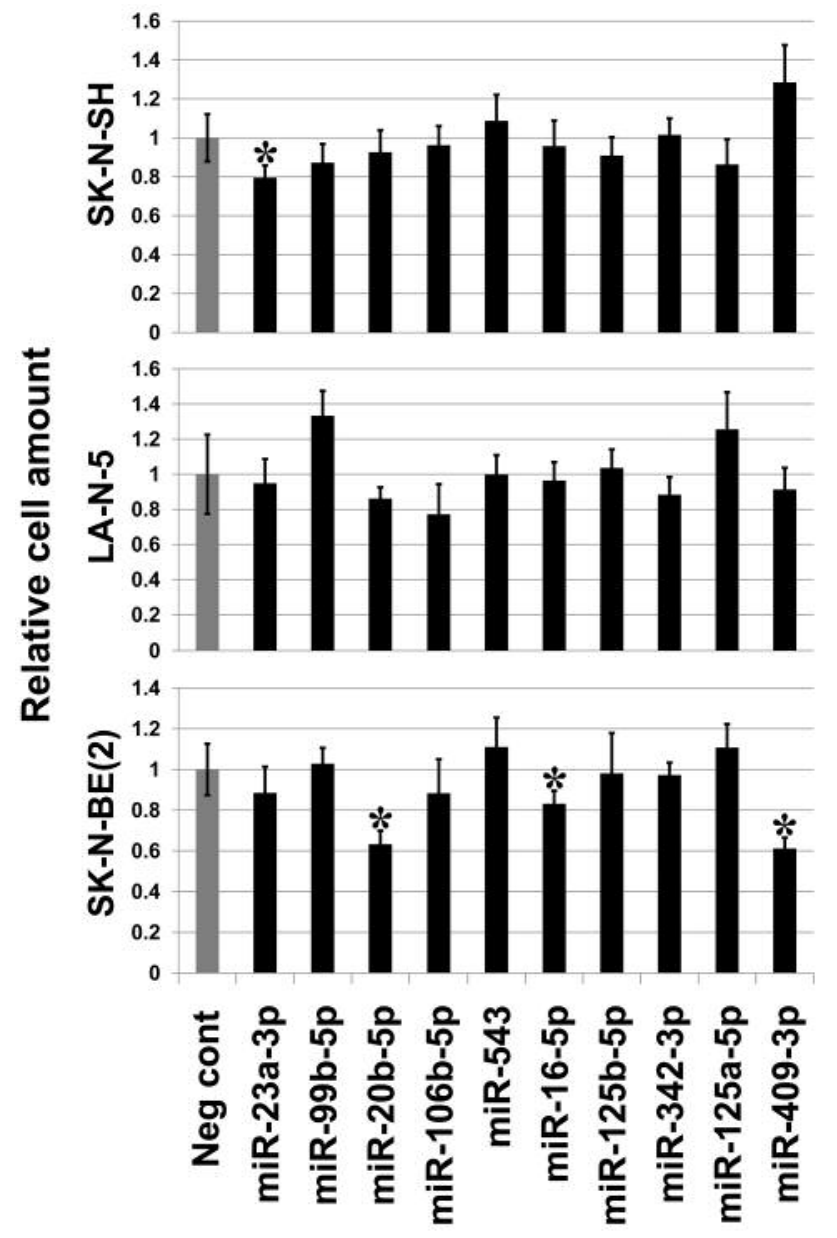

Figure 6. MicroRNA mimics for hsa-miR-16-5p, hsa-miR-20b-5p and hsa-miR-409-3p suppress cell growth of $S K-N-B E(2)$. Introduction of mimics for the three microRNA reduced cell proliferation of $S K-N-B E(2)$ compared to negative control mimic (Neg cont). The mimic for hsa-miR$23 a-3 p$ showed a weak cell proliferation inhibitory effect on $S K-N-S H$. Asterisks indicate statistical significance (p-value less than 0.05) between the negative control (Neg cont) and the mimic. Bar: Standard deviation.

6 Abbou S, Lanvers-Kaminsky C, Daudigeos-Dubus E, LE Dret L, Laplace-Builhe C, Molenaar J, Vassal G, Geoerger B; within the ITCC Biology and Preclinical Evaluation Committee: Pololike kinase inhibitor volasertib exhibits antitumor activity and synergy with vincristine in pediatric malignancies. Anticancer Res 36: 599-609, 2016.

7 Wang K, Diskin SJ, Zhang H, Attiyeh EF, Winter C, Hou C, Schnepp RW, Diamond M, Bosse K, Mayes PA, Glessner J, Kim C, Frackelton E, Garris M, Wang Q, Glaberson W, Chiavacci R, Nguyen L, Jagannathan J, Saeki N, Sasaki H, Grant SF, Iolascon A, Mosse YP, Cole KA, Li H, Devoto M, McGrady PW, London WB, Capasso M, Rahman N, Hakonarson H and Maris JM: Integrative genomics identifies LMO1 as a neuroblastoma oncogene. Nature 469: 216-220, 2011. 
8 Oldridge DA, Wood AC, Weichert-Leahey N, Crimmins I, Sussman R, Winter C, McDaniel LD, Diamond M, Hart LS, Zhu S, Durbin AD, Abraham BJ, Anders L, Tian L, Zhang S, Wei JS, Khan J, Bramlett K, Rahman N, Capasso M, Iolascon A, Gerhard DS, Guidry Auvil JM, Young RA, Hakonarson H, Diskin SJ, Look AT and Maris JM: Genetic predisposition to neuroblastoma mediated by a LMO1 super-enhancer polymorphism. Nature 528: 418-421, 2015.

9 Saeki N, Saito A, Sugaya Y, Amemiya M, Ono H, Komatsuzaki R, Yanagihara K and Sasaki H: Chromatin immunoprecipitation and DNA sequencing identified a LIMS1/ILK pathway regulated by an oncogenic transcription factor LMO1 in neuroblastoma. Cancer Genomics Proteomics 15: 165-174, 2018.

10 Hannigan G, Troussard AA and Dedhar S: Integrin-linked kinase: a cancer therapeutic target unique among its ILK. Nat Rev Cancer 5: 51-63, 2005.

11 Lee SL, Hsu EC, Chou CC, Chuang HC, Bai LY, Kulp SK and Chen CS: Identification and characterization of a novel integrinlinked kinase inhibitor. J Med Chem 54: 6364-6374, 2011.

12. Dougherty GW, Jose C, Gimona M and Cutler ML: The Rsu-1PINCH1-ILK complex is regulated by Ras activation in tumor cells. Eur J Cell Biol 87: 721-734, 2008.

13 Krol J, Loedige I and Filipowicz W: The widespread regulation of microRNA biogenesis, function and decay. Nat Rev Genet 11: 597-610, 2010.

14 Bartel DP: Metazoan MicroRNAs. Cell 173: 20-51, 2018.

15 Buechner J, Tømte E, Haug BH, Henriksen JR, Løkke C, Flægstad T and Einvik C: Tumour-suppressor microRNAs let-7 and mir-101 target the proto-oncogene MYCN and inhibit cell proliferation in $\mathrm{MYCN}$-amplified neuroblastoma. Br J Cancer 105: 296-303, 2011.

16 Wei JS, Song YK, Durinck S, Chen QR, Cheuk AT, Tsang P,Zhang Q, Thiele CJ, Slack A, Shohet J and Khan J: The MYCN oncogene is a direct target of miR-34a. Oncogene 27: 5204-5213, 2008.

17 Gherardi S, Valli E, Erriquez D and Perini G: MYCN-mediated transcriptional repression in neuroblastoma: the other side of the coin. Front Oncol 3: 42, 2013.

18 Shu R, Wong W, Ma QH, Yang ZZ, Zhu H, Liu FJ, Wang P, Ma J, Yan S, Polo JM, Bernard CC, Stanton LW, Dawe GS and Xiao ZC: APP intracellular domain acts as a transcriptional regulator of miR-663 suppressing neuronal differentiation. Cell Death Dis 6: e1651, 2015.

19 Roush S and Slack FJ: The let-7 family of microRNAs. Trends Cell Biol 18: 505-516, 2008.

20 Ricarte-Filho JC, Fuziwara CS, Yamashita AS, Rezende E, daSilva MJ and Kimura ET: Effects of let-7 microRNA on cell growth and differentiation of papillary thyroid cancer. Transl Oncol 2: 236-241, 2009.

21 Johnson CD, Esquela-Kerscher A, Stefani G, Byrom M, Kelnar K, Ovcharenko D, Wilson M, Wang X, Shelton J, Shingara J, Chin L, Brown D and Slack FJ: The let-7 microRNA represses cell proliferation pathways in human cells. Cancer Res 67: 7713$7722,2007$.

22 Wong TS, Man OY, Tsang CM, Tsao SW, Tsang RK, Chan JY, Ho WK, Wei WI and To VS: MicroRNA let-7 suppresses nasopharyngeal carcinoma cells proliferation through downregulating c-Myc expression. J Cancer Res Clin Oncol 137: 415422, 2011.
23 Liang S, He L, Zhao X, Miao Y, Gu Y, Guo C, Xue Z, Dou W, Hu F, Wu K, Nie Y and Fan D: MicroRNA let-7f inhibits tumor invasion and metastasis by targeting MYH9 in human gastric cancer. PLoS One 6: e18409, 2011.

24 Liu JM, Long XH, Zhang GM, Zhou Y, Chen XY, Huang SH, Liu ZL and Zhang ZH: Let-7g reverses malignant phenotype of osteosarcoma cells by targeting Aurora-B. Int J Clin Exp Pathol 7: 4596-4606, 2014.

25 Piskounova E, Viswanathan SR, Janas M, LaPierre RJ, Daley GQ, Sliz P and Gregory RI: Determinants of microRNA processing inhibition by the developmentally regulated RNAbinding protein Lin28. J Biol Chem 283: 21310-21314, 2008.

26 Molenaar JJ, Domingo-Fernández R, Ebus ME, Lindner S, Koster J, Drabek K, Mestdagh P, van Sluis P, Valentijn LJ, van Nes J, Broekmans M, Haneveld F, Volckmann R, Bray I, Heukamp L, Sprüssel A, Thor T, Kieckbusch K, Klein-Hitpass L, Fischer M, Vandesompele J, Schramm A, van Noesel MM, Varesio L, Speleman F, Eggert A, Stallings RL, Caron HN, Versteeg R and Schulte JH: LIN28B induces neuroblastoma and enhances MYCN levels via let-7 suppression. Nat Genet 44: 1199-1206, 2012.

27 Rybak A, Fuchs H, Smirnova L, Brandt C, Pohl EE, Nitsch R and Wulczyn FG: A feedback loop comprising lin-28 and let-7 controls pre-let-7 maturation during neural stem-cell commitment. Nat Cell Biol 10: 987-993, 2008.

28 Cole KA, Attiyeh EF, Mosse YP, Laquaglia MJ, Diskin SJ, Brodeur GM and Maris JM: A functional screen identifies miR$34 \mathrm{a}$ as a candidate neuroblastoma tumor suppressor gene. Mol Cancer Res 6: 735-742, 2008.

29 Tivnan A, Tracey L, Buckley PG, Alcock LC, Davidoff AM and Stallings RL: MicroRNA-34a is a potent tumor suppressor molecule in vivo in neuroblastoma. BMC Cancer 11: 33, 2011.

30 Xue TM, Tao LD, Zhang M, Xu GC, Zhang J and Zhang PJ: miR-20b overexpression is predictive of poor prognosis in gastric cancer. Onco Targets Ther 8: 1871-1876, 2015.

31 Ahmad A, Ginnebaugh KR, Sethi S, Chen W, Ali R, Mittal S and Sarkar FH: miR-20b is up-regulated in brain metastases from primary breast cancers. Oncotarget 6: 12188-12195, 2015.

32 Zhu J, Chen L, Zou L, Yang P, Wu R, Mao Y, Zhou H, Li R, Wang K, Wang W, Hua D and Zhang X: MiR-20b, -21, and -130b inhibit PTEN expression resulting in B7-H1 over-expression in advanced colorectal cancer. Hum Immunol 75: 348-353, 2014.

33 Park SL, Cho TM, Won SY, Song JH, Noh DH, Kim WJ and Moon SK: MicroRNA-20b inhibits the proliferation, migration and invasion of bladder cancer EJ cells via the targeting of cell cycle regulation and Sp-1-mediated MMP-2 expression. Oncol Rep 34: 1605-1612, 2015.

34 Sun YX, Yang J, Wang PY, Li YJ, Xie SY and Sun RP: Cisplatin regulates SH-SY5Y cell growth through downregulation of BDNF via miR-16. Oncol Rep 30: 2343-2349, 2013.

35 Zheng B, Liang L, Huang S, Zha R, Liu L, Jia D, Tian Q, Wang Q, Wang C, Long Z, Zhou Y, Cao X, Du C, Shi Y and He X: MicroRNA-409 suppresses tumour cell invasion and metastasis by directly targeting radixin in gastric cancers. Oncogene 31 : 4509-4516, 2012.

Received July 8, 2018

Revised July 19, 2018

Accepted July 23, 2018 